\title{
Influence of STAT4 Polymorphism in Primary Sjögren's Syndrome
}

\author{
ROGELIO J. PALOMINO-MORALES, LINA-MARCELA DIAZ-GALLO, TORSTEN WITTE, JUAN-MANUEL ANAYA, \\ and JAVIER MARTÍN
}

ABSTRACT. Objective. To examine the influence of STAT4 rs7574865 gene polymorphism on patients with primary Sjögren's syndrome (SS).

Methods. Two different cohorts were studied: 69 patients with primary SS and 296 controls from Colombia and 108 patients with primary SS and 227 controls from Germany. Samples were genotyped for the STAT4 rs7574865 single-nucleotide polymorphism with a predesigned TaqMan single-nucleotide polymorphism genotyping assay. We carried out a metaanalysis of our results combined with data published to date.

Results. Although no significant differences were observed in the allele frequencies of STAT4 rs7574865 gene polymorphism between patients and controls in Colombians ( $\mathrm{p}=0.28$, OR 1.24, 95\% CI 0.82-1.87) and Germans ( $\mathrm{p}=0.08$, OR $1.40,95 \%$ CI $0.96-2.02)$, the metaanalysis disclosed a significant effect of the $\mathrm{T}$ allele on disease $\left(\mathrm{p}=4.7 \times 10^{-6}\right.$, OR $1.40,95 \%$ CI $\left.1.21-1.62\right)$.

Conclusion. These data reinforce the influence of STAT4 gene on primary SS and as a general autoimmune gene. (First Release April 1 2010; J Rheumatol 2010;37:1016-9; doi:10.3899/ jrheum.091007)

Key Indexing Terms:

STAT4 SJÖGREN'S SYNDROME

Sjögren's syndrome (SS) is a chronic autoimmune disease characterized by progressive lymphocytic and plasma cell infiltration of the salivary and lachrymal glands, accompanied by the production of autoantibodies leading to xerostomia and keratoconjunctivitis sicca (sicca symptoms). SS may occur alone (primary SS; pSS) or in association with other autoimmune diseases (secondary SS; sSS), of which the most frequent are Hashimoto's thyroiditis and rheumatoid arthritis (RA). The powerful influence of genetic predisposition on susceptibility is usually based on disease concordance rates in monozygotic twins. Although genetic

From the Instituto de Parasitología y Biomedicina "López-Neyra", Consejo Superior de Investigaciones Científicas, Granada, Spain; the Cellular Biology and Immunogenetics Unit, Corporación para Investigaciones Biológicas, Universidad del Rosario, Medellin, Colombia; and Department of Clinical Immunology, Medical School Hannover, Hannover, Germany.

Supported by the Junta de Andalucía, grant CTS-1880, and by Universidad del Rosario, Medellin, Colombia.

R.J. Palomino-Morales, PhD; L-M. Diaz-Gallo, MSc, Instituto de Parasitología y Biomedicina "López-Neyra", Consejo Superior de Investigaciones Científicas; T. Witte, MD, PhD, Department of Clinical Immunology, Medical School Hannover; J-M. Anaya, MD, PhD, Cellular Biology and Immunogenetics Unit, Corporación para Investigaciones Biológicas, Universidad del Rosario; J. Martín, MD, PhD, Instituto de Parasitología y Biomedicina "López-Neyra", Consejo Superior de Investigaciones Científicas.

Address correspondence to Dr. R.J. Palomino-Morales, Instituto de Parasitología y Biomedicina "López-Neyra", CSIC, Parque Tecnológico de Ciencias de la Salud, Avenida del Conocimiento s/n, 18100 Armilla, Granada,Spain.E-mail:rpm@ipb.csic.es

Accepted for publication November 12, 2009.

\section{AUTOIMMUNITY GENETIC STUDIES}

studies in pSS twins have not been performed, the observed aggregation of autoimmune diseases in families of patients with pSS supports a genetic component in SS etiology ${ }^{1-4}$. The efforts to identify the genetic component of SS have relied on association studies for disease gene identification. However, robust analyses of candidate gene variants have not been undertaken and no linkage study has been reported to date. In the absence of chromosomal regions identified by linkage studies, research has focused on candidate gene approaches (by biological plausibility) rather than on positional approaches. Association with HLA genes has been largely described and confirmed ${ }^{5-7}$. Genes outside the HLA region have also been associated with pSS; nevertheless these positive associations, including $P T P N 22^{8,9}$ and $C T L A$, have proven difficult to replicate. Recently, an association of STAT4 gene polymorphism (rs7574865) at 2q32 with SS has been reported ${ }^{12,13}$. Our objective was to assess the influence of STAT4 rs7574865 polymorphism on pSS in German and Colombian populations, and to evaluate the global influence of this variant in disease susceptibility with a metaanalysis.

\section{MATERIALS AND METHODS}

Study population. Peripheral blood samples were obtained from 2 unrelated cohorts of pSS patients and controls. The Colombian cohort consisted of 69 pSS patients and 296 healthy controls and the German cohort 108 pSS patients and 227 healthy controls. All patients fulfilled the international classification criteria ${ }^{14}$ for pSS. Patients and controls were all Caucasian and were matched for age (by mean age) and for sex (by frequency matching). Written informed consent was obtained from all subjects, and the study was approved by the local ethics committee of each center. 
Demographic characteristics of the patients and controls in each population have been described ${ }^{15-17}$.

For the metaanalysis we combined data from North American (case-control ratio 120/1112), Norwegian (case-control ratio 228/669), and Swedish (case-control ratio 140/148) cohorts ${ }^{12,13}$ with our findings. It is important to note that Nordmark, et al ${ }^{13}$ analyzed rs7582694 STAT4 gene polymorphism, which is a perfect proxy of rs 7574865 .

Genotyping for STAT4 polymorphism. Samples were genotyped for STAT4 rs7574865 using a polymerase chain reaction system with a predeveloped TaqMan allelic discrimination assay (Applied Biosystems, Foster City, CA, USA $)^{18}$. Duplicate samples and negative controls were included to check the accuracy of genotyping. The genotyping success rate was $\geq 96 \%$.

Statistical analysis. We used the chi-square test for Hardy-Weinberg equilibrium and statistical analysis to compare allelic and genotypic distributions. Odds ratios (OR) and 95\% confidence intervals (95\% CI) were calculated according to Woolf's method ${ }^{19}$ using the Statcalc program (EpiInfo 2002, Centers for Disease Control and Prevention, Atlanta, GA, USA). $P$ values $<0.05$ were considered statistically significant.

To estimate the common effect size of the T allele on disease, a metaanalysis of previous results together with our own was performed. Characteristics of studies included in the metaanalysis are shown in Figure 1. The metaanalysis was conducted using StatsDirect software (StatsDirect, Cheshire, UK). In all the studies, allele and genotyping frequencies were consistent with Hardy-Weinberg equilibrium in patients and controls. Since the number of studies and the average sample size were small, to calculate the inconsistency of the metaanalysis with a power $>80 \%$, pooled calculations of OR were obtained using random effect models ${ }^{20}$. Publication bias was investigated by funnel plotting. The significance of the intercept was determined by the $t$ test suggested by Egger.

The power of the study to detect an effect of a polymorphism on disease susceptibility was estimated for an OR of 1.4 (first described effect size), a type I error rate of 0.05 , dominant inheritance mode, and $0.005 \%$ of population risk. The power was calculated using Quanto version 0.5 software (Department of Preventive Medicine, University of Southern California, Los Angeles, CA, USA).

\section{RESULTS}

No deviation from Hardy-Weinberg equilibrium was observed in the study cohorts for the rs7574865 single-nucleotide polymorphism (SNP). Table 1 shows the STAT4 rs7574865 genotype and allele distributions for Colombian and German populations. The $\mathrm{T}$ allele increased the risk of developing pSS by $24 \%$ in Colombian subjects. The same trend was found in the German cohort, in which the frequencies of the $\mathrm{T}$ allele showed a clear trend of association $(\mathrm{p}=0.08$, OR $1.40,95 \%$ CI $0.96-2.02)$. Since the observed effect of the $\mathrm{T}$ allele was not significant due to low sample size ( $40 \%$ power for the Colombian and $45 \%$ for the German cohort), we combined data from previous studies in a metaanalysis in order to improve statistical power $(>99 \%$ in the metaanalysis). Interestingly, STAT4 $\mathrm{rs} 7574865 \mathrm{~T}$ allele frequencies were quite similar in patients and controls in all the populations, except for the Colombian population, where the $\mathrm{T}$ allele frequency in pSS patients was similar to the frequencies in patients with RA and systemic lupus erythematosus (SLE) reported before ${ }^{18}$. Figure 1 shows results of the metaanalysis of all studies with published allele frequencies for STAT4 rs7574865 in pSS, including the present study. There was no statistically significant evidence for heterogeneity of OR among the studies for this polymorphism in $\mathrm{pSS}$, and the fixed-effects model was chosen $\left(\mathrm{I}^{2}=0 \%\right)$. Metaanalysis of all 5 cohorts using the Mantel-Haenszel test revealed a highly significant association of this variant with pSS (pooled OR 1.40, 95\% CI 1.21-1.62, $\mathrm{p}=4.7 \times 10^{-6}$ ). No publication bias was found in these studies; the Egger test was not statistically significant (bias $=1.09,95 \% \mathrm{CI}=$ -1.35651 to $3.53, \mathrm{p}=0.19$ ), with symmetrical funnel plots (data not shown).

\section{DISCUSSION}

Our study adds further evidence indicating an influence of

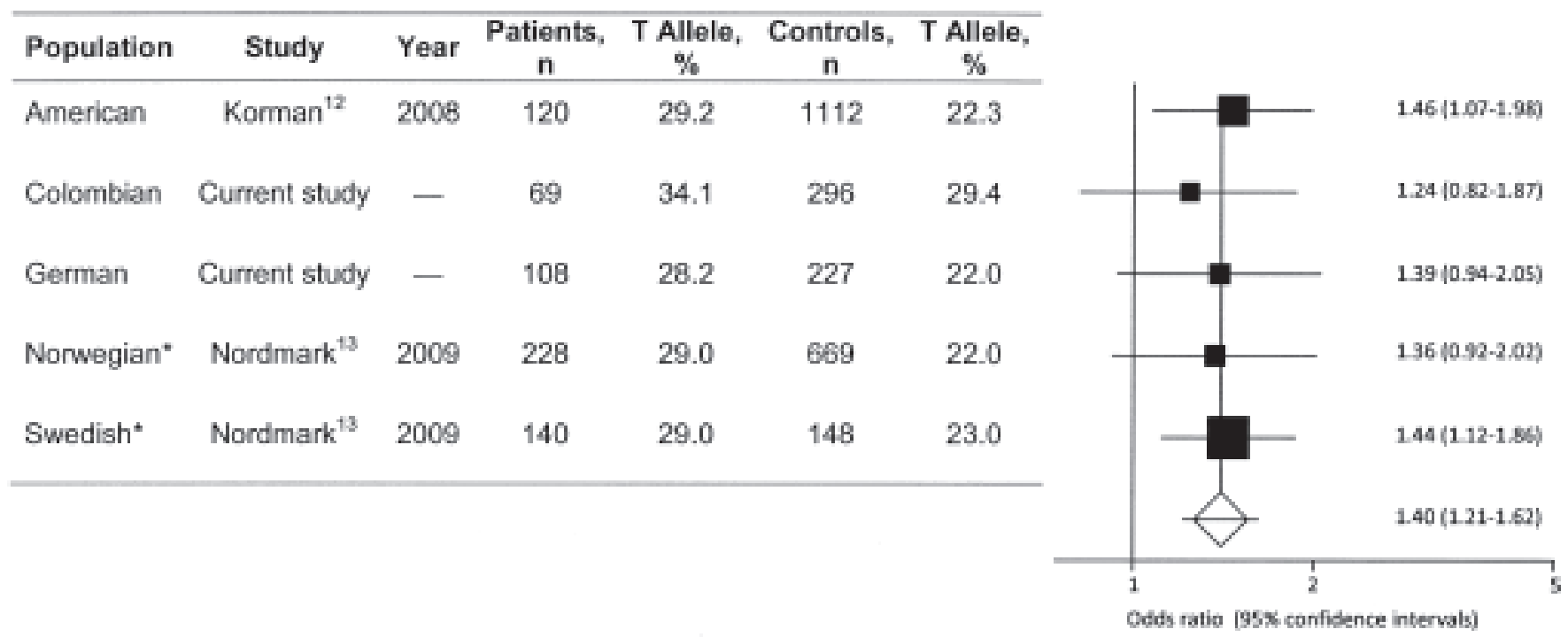

Figure 1. Pooled data for the STAT4 rs7574865 T allele frequency of North American, Colombian, German, Norwegian, and Swedish populations. OR estimate of each study is marked with a square; the size of the square represents the weight that study exerts in the metaanalysis. Confidence intervals of pooled estimates are shown as a horizontal line. No asymmetry was found, as indicated by the $\mathrm{p}$ value of Egger's t test: bias $=-1.46(95 \% \mathrm{CI}-3.44$ to 1.14$)$, $\mathrm{p}=$ 0.20. *Data correspond to rs 7582694 STAT4 polymorphism that is a perfect proxy of rs 7574865 .

Personal non-commercial use only. The Journal of Rheumatology Copyright (C) 2010. All rights reserved 
Table 1. Genotype and allele frequencies of the rs7574865 STAT4 polymorphism in healthy controls and patients with primary SS.

\begin{tabular}{lcccc}
\hline STAT4 rs7574865 & $\mathrm{pSS}$ & Controls & $\mathrm{p}$ & OR (95\% CI) \\
\hline Colombians & $\mathrm{n}=69(\%)$ & $\mathrm{n}=296(\%)$ & & \\
GG & $28(40.6)$ & $152(51.4)$ & 0.11 & $0.50(0.37-1.14)$ \\
GT & $35(50.7)$ & $114(38.5)$ & 0.06 & $1.64(0.94-2.88)$ \\
TT & $6(8.7)$ & $30(10.1)$ & 0.71 & $0.84(0.30-2.25)$ \\
G & $91(65.9)$ & $418(70.6)$ & 0.28 & $0.81(0.53-1.22)$ \\
T & $47(34.1)$ & $174(29.4)$ & 0.28 & $1.24(0.82-1.87)$ \\
Germans & $\mathrm{n}=108(\%)$ & $\mathrm{n}=227(\%)$ & & $0.67(0.41-1.09)$ \\
GG & $55(50.9)$ & $138(60.8)$ & 0.09 & $1.36(0.83-2.24)$ \\
GT & $45(41.7)$ & $78(34.4)$ & 0.19 & $1.57(0.56-4.37)$ \\
TT & $8(7.4)$ & $11(4.8)$ & 0.34 & $0.72(0.49-1.04)$ \\
G & $155(71.8)$ & $354(78)$ & 0.08 & $1.40(0.96-2.02)$ \\
T & $61(28.2)$ & $100(22)$ & 0.08 & \\
\hline
\end{tabular}

STAT4 rs7574865 T allele in pSS, and confirms STAT4 as one of the most important and replicable genes influencing susceptibility to pSS apart from the HLA region.

The association of rs7574865 variant in the STAT4 gene was initially reported in Korean patients with $\mathrm{RA}^{20 \mathrm{a}}$, and almost at the same time in Caucasian patients with RA and $\mathrm{SLE}^{21}$. These associations were replicated later in different populations ${ }^{18,22-25}$ and in autoimmune diseases such as type I diabetes ${ }^{26,27}$ and systemic sclerosis ${ }^{28}$. Together, these data suggest that STAT4 could be a useful genetic marker of autoimmunity, and they add further evidence for a common genetic origin of diverse autoimmune diseases ${ }^{29}$. Nevertheless, there are other autoimmune diseases in which STAT4 rs7465865 showed no influence, such as giant cell arteritis $^{30}$ and multiple sclerosis ${ }^{26}$; the reason STAT4 has different effects in different autoimmune diseases remains unknown.

STAT4 genes encode a transcription factor that transmits signals induced by interleukin 12 (IL-12), IL-23, and type 1 interferon ${ }^{31}$. A major action of IL-12 through STAT4 signaling is to promote the differentiation of naive CD4+ T cells into T-helper 1 (Th1) cells, which produce interferon- $\gamma$. These Th1 cells are thought to drive the chronic autoimmune response. STAT4 is also important for the development of IL-17-secreting Th cells in response to IL-23 ${ }^{32}$. As both lineages are master regulators of the etiopathology of pSS in humans ${ }^{33,34}$, STAT4 may exert its influence through defective signaling in these pathways.

Although it seems clear that STAT4 plays a key role in several pathways in autoimmunity, the functional role(s) of the associated polymorphism(s) remains to be elucidated. The rs 7574865 STAT4 variant is located at the third intron of the gene, suggesting a role in STAT4 splicing. Nevertheless, Abelson, et $a l^{25}$ observed no differences in splicing of the gene in peripheral blood mononuclear cells (PBMC). Instead, they reported a correlation between expression levels of STAT4 in PBMC and the risk allele of the STAT4 rs7574865-associated SNP. Additional studies are needed to clarify the role of STAT4 as a novel marker for autoimmune diseases.

\section{ACKNOWLEDGMENT}

We thank all the participants in this study.

\section{REFERENCES}

1. Reveille JD, Wilson RW, Provost TT, Bias WB, Arnett FC. Primary Sjogren's syndrome and other autoimmune diseases in families. Prevalence and immunogenetic studies in six kindreds. Ann Intern Med 1984;101:748-56.

2. Lichtenfeld JL, Kirschner RH, Wiernik PH. Familial Sjogren's syndrome with associated primary salivary gland lymphoma. Am J Med 1976;60:286-92.

3. Sabio JM, Milla E, Jimenez-Alonso J. A multicase family with primary Sjogren's syndrome. J Rheumatol 2001;28:1932-4.

4. Anaya JM, Castiblanco J, Tobon GJ, Garcia J, Abad V, Cuervo H, et al. Familial clustering of autoimmune diseases in patients with type 1 diabetes mellitus. J Autoimmun 2006;26:208-14.

5. Harley JB, Alexander EL, Bias WB, Fox OF, Provost TT, Reichlin M, et al. Anti-Ro (SS-A) and anti-La (SS-B) in patients with Sjogren's syndrome. Arthritis Rheum 1986;29:196-206.

6. Harley JB, Reichlin M, Arnett FC, Alexander EL, Bias WB, Provost TT. Gene interaction at HLA-DQ enhances autoantibody production in primary Sjogren's syndrome. Science 1986;232:1145-7.

7. Chused TM, Kassan SS, Opelz G, Moutsopoulos HM, Terasaki PI. Sjogren's syndrome association with HLA-Dw3. N Engl J Med 1977;296:895-7

8. Gomez LM, Anaya JM, Gonzalez CI, Pineda-Tamayo R, Otero W, Arango A, et al. PTPN22 C1858T polymorphism in Colombian patients with autoimmune diseases. Genes Immun 2005;6:628-31.

9. Ittah M, Gottenberg JE, Proust A, Hachulla E, Puechal X, Loiseau P, et al. No evidence for association between $1858 \mathrm{C} / \mathrm{T}$ singlenucleotide polymorphism of PTPN22 gene and primary Sjogren's syndrome. Genes Immun 2005;6:457-8.

10. Downie-Doyle S, Bayat N, Rischmueller M, Lester S. Influence of CTLA4 haplotypes on susceptibility and some extraglandular manifestations in primary Sjogren's syndrome. Arthritis Rheum 2006;54:2434-40.

11. Gottenberg JE, Loiseau P, Azarian M, Chen C, Cagnard N, Hachulla E, et al. CTLA-4 +49A/G and CT60 gene polymorphisms in primary Sjogren syndrome. Arthritis Res Ther 2007;9:R24.

12. Korman BD, Alba MI, Le JM, Alevizos I, Smith JA, Nikolov NP, et al. Variant form of STAT4 is associated with primary Sjogren's syndrome. Genes Immun 2008;9:267-70. 
13. Nordmark G, Kristjansdottir G, Theander E, Eriksson P, Brun JG, Wang C, et al. Additive effects of the major risk alleles of IRF5 and STAT4 in primary Sjogren's syndrome. Genes Immun 2009;10:68-76.

14. Vitali C, Bombardieri S, Jonsson R, Moutsopoulos HM, Alexander EL, Carsons SE, et al. Classification criteria for Sjogren's syndrome: a revised version of the European criteria proposed by the American-European Consensus Group. Ann Rheum Dis 2002;61:554-8.

15. Kabalak G, Dobberstein SB, Matthias T, Reuter S, The YH, Dorner $\mathrm{T}$, et al. Association of immunoglobulin-like transcript 6 deficiency with Sjogren's syndrome. Arthritis Rheum 2009;60:2923-5.

16. Witte T, Bierwirth J, Schmidt RE, Matthias T. Antibodies against $\alpha$-fodrin are associated with dry eyes and mouth in the general population [letter]. J Rheumatol 2006;33:1713-4.

17. Anaya JM, Correa PA, Herrera M, Eskdale J, Gallagher G. Interleukin 10 (IL-10) influences autoimmune response in primary Sjogren's syndrome and is linked to IL-10 gene polymorphism. J Rheumatol 2002;29:1874-6.

18. Palomino-Morales RJ, Rojas-Villarraga A, Gonzalez CI, Ramirez G, Anaya JM, Martin J. STAT4 but not TRAF1/C5 variants influence the risk of developing rheumatoid arthritis and systemic lupus erythematosus in Colombians. Genes Immun 2008;9:379-82.

19. Woolf B. On estimating the relation between blood group and disease. Ann Hum Genet 1955;19:251-3.

20. Huedo-Medina TB, Sanchez-Meca J, Marin-Martinez F, Botella J. Assessing heterogeneity in meta-analysis: Q statistic or $\mathrm{I}^{2}$ index? Psychol Methods 2006;11:193-206.

20a. Lee HS, Remmers EF, Le JM, Kastner DL, Bae SC, Gregersen PK. Association of STAT4 with rheumatoid arthritis in the Korean population. Mol Med 2007;13:455-60.

21. Remmers EF, Plenge RM, Lee AT, Graham RR, Hom G, Behrens TW, et al. STAT4 and the risk of rheumatoid arthritis and systemic lupus erythematosus. N Engl J Med 2007;357:977-86.

22. Taylor KE, Remmers EF, Lee AT, Ortmann WA, Plenge RM, Tian $\mathrm{C}$, et al. Specificity of the STAT4 genetic association for severe disease manifestations of systemic lupus erythematosus. PLoS Genet 2008;4:e1000084.

23. Orozco G, Alizadeh BZ, Delgado-Vega AM, Gonzalez-Gay MA, Balsa A, Pascual-Salcedo D, et al. Association of STAT4 with rheumatoid arthritis: a replication study in three European populations. Arthritis Rheum 2008;58:1974-80.
24. Sigurdsson S, Nordmark G, Garnier S, Grundberg E, Kwan T, Nilsson O, et al. A risk haplotype of STAT4 for systemic lupus erythematosus is over-expressed, correlates with anti-dsDNA and shows additive effects with two risk alleles of IRF5. Hum Mol Genet 2008;17:2868-76.

25. Abelson A, Delgado-Vega A, Kozyrev S, Sánchez E, Velázquez-Cruz R, Eriksson N, et al. STAT4 associates with SLE through two independent effects that correlate with gene expression and act additively with IRF5 to increase risk. Ann Rheum Dis 2009;68:1746-53.

26. Martinez A, Varade J, Marquez A, Cenit MC, Espino L, Perdigones $\mathrm{N}$, et al. Association of the STAT4 gene with increased susceptibility for some immune-mediated diseases. Arthritis Rheum 2008;58:2598-602.

27. Lee HS, Park H, Yang S, Kim D, Park Y. STAT4 polymorphism is associated with early-onset type 1 diabetes, but not with late-onset type 1 diabetes. Ann NY Acad Sci 2008;1150:93-8.

28. Rueda B, Broen J, Simeon C, Hesselstrand R, Diaz B, Suarez H, et al. The STAT4 gene influences the genetic predisposition to systemic sclerosis phenotype. Hum Mol Genet 2009;18:2071-7.

29. Pearce SH, Merriman TR. Genetic progress towards the molecular basis of autoimmunity. Trends Mol Med 2006;12:90-8.

30. Palomino-Morales R, Vazquez-Rodriguez TR, Morado IC, Castaneda S, Ortego-Centeno N, Miranda-Filloy JA, et al. Lack of association between STAT4 gene polymorphism and biopsy-proven giant cell arteritis. J Rheumatol 2009;36:1021-5.

31. Watford WT, Hissong BD, Bream JH, Kanno Y, Muul L, O'Shea JJ. Signaling by IL-12 and IL-23 and the immunoregulatory roles of STAT4. Immunol Rev 2004;202:139-56.

32. Skapenko A, Leipe J, Lipsky PE, Schulze-Koops H. The role of the $\mathrm{T}$ cell in autoimmune inflammation. Arthritis Res Ther 2005;7 Suppl 2:S4-14.

33. Mitsias DI, Tzioufas AG, Veiopoulou C, Zintzaras E, Tassios IK, Kogopoulou O, et al. The Th1/Th2 cytokine balance changes with the progress of the immunopathological lesion of Sjogren's syndrome. Clin Exp Immunol 2002;128:562-8.

34. Nguyen CQ, Hu MH, Li Y, Stewart C, Peck AB. Salivary gland tissue expression of interleukin-23 and interleukin-17 in Sjogren's syndrome: findings in humans and mice. Arthritis Rheum 2008;58:734-43. 